\title{
Effects of Vitamin A Deficiency and Repletion on Rat Insulin Secretion In Vivo and In Vitro from Isolated Islets
}

\author{
B. S. Chertow, ${ }^{\star}$ W. S. Blaner, ${ }^{\ddagger}$ N. G. Baranetsky, ${ }^{*}$ W. I. Sivitz, ${ }^{\star}$ M. B. Cordle, ${ }^{\star}$ D. Thompson, ${ }^{\star}$ and P. Meda \\ *Medical Service, Veterans Administration Medical Center, and Department of Medicine, Marshall University School of Medicine, \\ Huntington, West Virginia 25701; ${ }^{\ddagger}$ Department of Medicine, Columbia University College of Physicians \& Surgeons, New York, \\ New York 10032; 'Institute of Histology and Embryology, University of Geneva, Geneva, Switzerland
}

\begin{abstract}
We studied the effects of vitamin $A$ deficiency and repletion on rat insulin release and islet cellular retinol binding protein (CRBP) and cellular retinoic acid binding protein (CRABP). Biphasic insulin release from vitamin A-deficient perifused islets was markedly impaired. Release remained impaired with retinoic acid (RA) repletion, $2 \mu \mathrm{g} / \mathrm{g}$ diet compared to release from islets of rats repleted with retinol in the form of retinyl palmitate, 4 $\mu \mathrm{g} / \mathrm{g}$ diet. Release normalized with RA, $8 \mu \mathrm{g} / \mathrm{g}$ diet. Vitamin A deficiency did not affect islet insulin content, cell size, number or structure. In vivo, vitamin A-deficient rats had impaired glucose-induced acute insulin release and glucose intolerance, which improved with repletion. Normal islets had greater concentrations of CRBP than CRABP; vitamin A deficiency reduced CRBP but not CRABP levels. We conclude retinol is required for normal insulin secretion. Retinoic acid may substitute for retinol in this function.
\end{abstract}

\section{Introduction}

Vitamin A deficiency is a world health problem leading to poor growth, blindness, and reproductive failure (1). At the cellular level, vitamin A deficiency leads to abnormalities in cellular differentiation, glycoprotein synthesis, cell-to-cell adhesion, and changes in a wide variety of other membrane functions $(2,3)$. These membrane functions are universal to cell biology and are potentially important in secretory cells. With the exception of its role in the visual cycle (4), the molecular mechanisms responsible for vitamin A function are not yet well defined. Recent studies suggest that retinoids affect gene expression in target cells. Retinol and retinoic acid bind to specific intracellular binding proteins, cellular retinol binding protein (CRBP) ${ }^{1}$ and cellular retinoic acid binding protein (CRABP), respectively. Although the functions of these binding proteins are not known, it has been suggested that they might transport the retinoid to, or fa-

\footnotetext{
Address reprint requests to Dr. Chertow.

Presented in part in abstract form at the 67th Annual Meeting of the Endocrine Society, June 1985, and at the Annual Meeting of the American for Clinical Research, May 1986 (Clin. Res. 34:389a). 1986.

Received for publication 19 August 1985 and in revised form 12 June
}

1. Abbreviations used in this paper: CRABP, cellular retinoic acid binding protein; CRBP, cellular retinol binding protein; RA, retinoic acid; RBP, retinol binding protein; $R P$, retinyl palmitate; TTR, transthyretin.

J. Clin. Invest.

(c) The American Society for Clinical Investigation, Inc. 0021-9738/87/01/0163/07 \$1.00

Volume 79, January 1987, 163-169 cilitate its action in the nucleus to affect gene expression (similar to steroid hormones) (5). In addition, retinol binding protein (RBP), a specific plasma binding protein, circulates in plasma. Plasma RBP is synthesized in the liver and serves to mobilize retinol from the liver. When released into the circulation, retinolRBP complexes with transthyretin (TTR, more commonly known as prealbumin) and circulates normally in a one-to-one molar ratio (retinol-RBP-TTR [6]).

Recent studies (7) have demonstrated the presence of relatively high levels of CRBP, CRABP, TTR, and RBP in pancreatic rat islets. We have also shown that retinoids influence islet insulin secretion, ultrastructure and cell aggregation (8-10). These findings suggest that retinoids and their binding proteins may have an important role in islet function. To test for a functional role of vitamin A, we studied the effects of the retinol and retinoic acid deficiency on insulin secretion. We also determined whether retinol or retinoic acid deficiency had effects on the islet concentrations of cellular retinoid binding proteins which, in turn, might modulate vitamin A action.

\section{Methods}

Vitamin A deficiency model and insulin secretion. Two potential problems exist in models of vitamin A-deficiency: (a) Rats may not synchronously develop complete vitamin A deficiency, and $(b)$ vitamin A-deficient rats have decreased food intake and growth which may affect insulin secretion (11). To assure a complete deficiency of retinol and retinoic acid and to minimize the variables of decreased food intake on insulin release, we adapted the model of Olson et al., (12-14) with modifications. The model calls for cycles of rapid synchronously induced vitamin A deficiency while avoiding generalized nutritional deficiency. In this model, vitamin A-deficient rats are repeatedly cycled with dietary all trans-retinoic acid. Because all trans-retinoic acid is not stored in the liver and is rapidly metabolized and excreted, discontinuation of all trans-retinoic acid rapidly leads to vitamin A deficiency. In initial studies using commercially obtained rats, we observed a markedly variable time of onset of the signs and weight plateau of vitamin A deficiency, probably related to an excess of liver stores obtained from diverse dietary sources. Therefore, we modified the protocol to breed our own vitamin A deficient rats. For breeding, female Sprague-Dawley rats were fed Purina rat chow until midway into pregnancy, at $\sim 10 \mathrm{~d}$. Thereafter the rats received a powdered vitamin A deficient synthetic diet (Deluca diet number 11) $(15,16)$ supplemented with vitamins $D, E$, and $K$ prepared in our laboratory. The dams were kept on this synthetic vitamin A-deficient diet for the remainder of their pregnancy and through weaning. Pups had access only to the dams vitamin A-deficient diet. At $21 \mathrm{~d}$ the pups were placed in separate stainless steel cages with separate feed cups and maintained on a vitamin A-free diet. Rats were weighed three times a week. An example of weight changes in a retinoic acid-cycled rat during development of vitamin A deficiency (one cycle of retinoic acid repletion and withdrawal, followed by beginning of a test period) is shown in Fig. 1.

Weight curves for each rat and the mean for the group were constructed. As the rats grew, the onset of vitamin A deficiency between days 50 and 75 would be heralded by a weight plateau and sometimes 


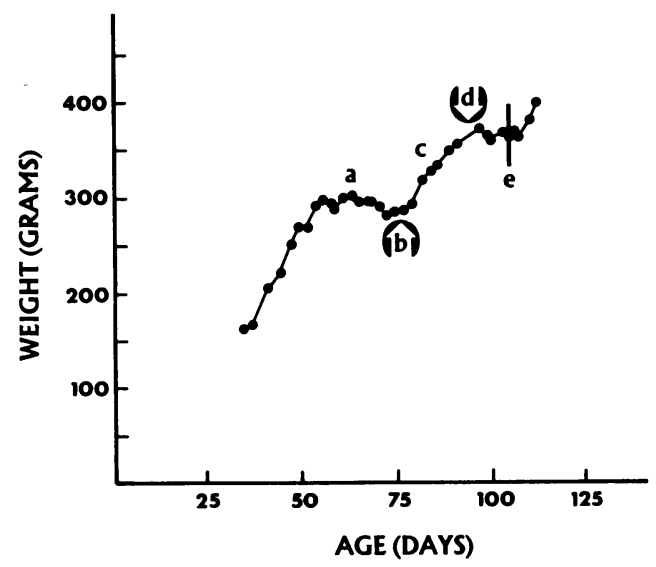

Figure 1. Vitamin A-deficiency model. Mean growth (body weight) of a single rat subjected to one retinoic acid cycle. Rat pups were kept on a vitamin A-free diet until depletion of endogenous stores indicated by a plateau in weight $(a)$ and signs of vitamin A deficiency. At day 75 , the first RA cycle was started ( $b$, arrow pointing $u p$ ) by supplementing the diet with RA, $2-\mu \mathrm{g} / \mathrm{g}$ diet for $18 \mathrm{~d}(c)$ followed by $(d, a r-$ row pointing down) a vitamin A-free diet for $10 \mathrm{~d}$ (18 on, 10 off cycle). Vertical bar at end of off period (e) indicates end of one cycle and start of a second RA cycle or a 14-d control or test diet, e.g., vitamin A-free, all trans-retinoic acid, $2 \mu \mathrm{g} / \mathrm{g}$ diet, or retinyl palmitate (RP), 4 $\mu \mathrm{g} / \mathrm{g}$ diet.

weight loss, which was followed shortly after by clinical signs, such as corneal porphyrin deposits, matting of the hair, blindness, and swollen salivary glands. When the growth curve of the group clearly showed a plateau in mean weight for at least $5 \mathrm{~d}$, the rats were then supplemented with all trans-retinoic acid, $2 \mu \mathrm{g} / \mathrm{g}$ diet. Within a few days of supplementation, although deficient in retinol, rats responded by resuming their growth rate, which was then maintained throughout the supplementation period. Clinical signs of vitamin A deficiency disappeared within a few days. After $18 \mathrm{~d}$ of all trans-retinoic acid supplementation, the rats were again placed on a vitamin A-deficient diet for $10 \mathrm{~d}$. During this vitamin A-deficient period, the growth curve would again plateau, and in some rats decrease, and clinical signs of vitamin A deficiency would reappear. After this second 10-d period of vitamin A deficiency, the rats were placed on special control or test diets for $14 \mathrm{~d}$. In some studies, rats were cycled a second time (18 d on RA, $10 \mathrm{~d}$ off vitamin A) and then placed on a test diet.

Synthetic retinyl palmitate and all trans-retinoic acid were kindly provided by Hoffmann-La Roche, Inc., Nutley, NJ. The retinyl palmitate and retinoic acid was prepared in Wesson vegetable oil as a stock solution that also contained DL-alpha-tocopherol to prevent oxidation of retinoid. Control rats also received DL-alpha tocopherol in Wesson oil. The solutions of retinoids in Wesson oil were prepared monthly, kept at $4^{\circ} \mathrm{C}$ in amber glass containers and added to the diet on a daily basis.

Experiments were designed to test for a role of retinol and retinoic acid in insulin release. In our first experiment, we tested whether vitamin A deficiency led to any impairment of insulin release. In the latter studies, after one repletion/depletion cycle, vitamin A-deficient rats were maintained on a totally vitamin A-deficient diet during a 14-d test period.

After observing impairment of insulin release in the above studies (see results), we determined whether repletion with all trans-retinoic acid, $2 \mu \mathrm{g} / \mathrm{g}$ diet, or retinol in the form of retinyl palmitate, $4 \mu \mathrm{g} / \mathrm{g}$ diet (a normal vitamin A content) (12), during a 14-d test period restored insulin release. These amounts of all trans-retinoic acid and retinyl palmitate were selected because they represent replacement doses of equimolar quantities of the two retinoids.

In a third experiment, the effect of retinoic acid repletion with a higher dose, $8-\mu \mathrm{g} / \mathrm{g}$ diet, was compared to repletion with retinyl palmitate, $4-\mu \mathrm{g} / \mathrm{g}$ diet.
At the end of the experimental test period, rat pancreases were removed and islets isolated and perifused by methods previously described $(8-10)$. In brief, pancreases were excised from anesthetized control or vitamin A-deficient male white rats, immediately minced and digested with $0.7 \%$ collagenase. Pancreases of A-deficient and repleted rats that were synchronously depleted of retinol after weaning by retinoic acid cycling do not look different than pancreases of rats fed vitamin A after weaning. Collagenase digestion time is adjusted to yield adequate numbers of intact islets for study. Digestion times of 7-7.5 min and islet yields from control and test pancreases in our experiments were similar and occasionally may be $30-60$ s less than noncycled rats fed vitamin A after weaning. Islets from vitamin A-deficient or control rats were isolated by hand from the digest and perifused in plastic chambers (Millipore Corp., Bedford, MA) at a flow rate of $1 \mathrm{ml} / \mathrm{min}$. For perifusion studies 50 islets from control or vitamin A-deficient rats were perifused in test chambers in each experiment. After a 60-min basal perifusion with Krebs-Ringer bicarbonate buffer containing $2.8 \mathrm{mM}$ glucose, a test perifusion was started with buffer containing concentrations of $16.7 \mathrm{mM}$ glucose. Samples were collected frequently (see points on figures) throughout the perifusion and radioimmunoassayed for insulin $(17,18)$. First or second phase or cumulative insulin release was determined by calculating the area under the curve for each phase.

At the same time that the pancreases were removed, samples of blood were obtained for vitamin A assay (19). Serum retinol was found to be $<2 \mu \mathrm{g} / \mathrm{dl}$ validating the vitamin A-deficient state.

Islet CRBP and CRABP. Islets were isolated from groups of normal and repleted vitamin A-deficient rats. Approximately 300 to 1,000 islets from three to five rats in each group $(n=1)$ were washed three to five times in phosphate-buffered saline pH 7.4 (PBS) and then rapidly frozen and stored until used for radioimmunoassay. Islets were then thawed and homogenized in $1 \mathrm{ml}$ of assay buffer containing $50 \mathrm{mM}$ imidazole buffer $\mathrm{pH} 7.4,0.79 \% \mathrm{NaCl}, 0.03 \%$ bovine serum albumin, $0.1 \%$ thiomerosal, $0.01 \%$ leupeptin, and $1.0 \%$ Triton X-100. CRBP and CRABP levels were determined by recently developed sensitive and specific radioimmunoassays for each protein $(7,20)$. Radioimmunoassays for CRBP and CRABP employed identical protocols. Both assays accurately detect 1 to $10 \mathrm{ng}$ of protein (CRBP or CRABP) per assay tube. Values were expressed as nanograms per islet.

Islet insulin and protein content. Islets were isolated from groups of normal, A-deficient, and retinoic acid- and retinyl palmitate-repleted rats. For measurement of insulin, islets were isolated from each rat digest $(n=1)$ and washed in buffer. 2-20 batches of 10 islets from each rat digest were added to $1.0 \mathrm{ml}$ of acid ethanol, sonicated for $1 \mathrm{~min}$, microcentrifuged, and the extract assayed for insulin $(n=1)$. For measurement of protein content, $\sim 300-1000$ islets were isolated from three to five rats and homogenized, and the protein content of homogenate $(n=1)$ measured by the method of Bradford (21).

In vivo glucose tolerance and insulin secretion. Normal, vitamin Adeficient, and retinoic acid- and retinyl palmitate-repleted rats had an intravenous glucose tolerance test after an overnight $16-\mathrm{h}$ fast. Normal rats, weighing $300-400 \mathrm{~g}$, were not made vitamin A-deficient, were on a synthetic diet and received retinyl palmitate, $6.6-\mu \mathrm{g} / \mathrm{g}$ diet. Vitamin A-deficient and repleted rats were prepared as described above for studies in vitro. To assure injection of the total glucose bolus and adequate sample volume without hemolysis (which interferes with our insulin assay), studies measuring insulin release and glucose tolerance were performed separately; rats were anesthetized with ketamine hydrochloride (Bristol Laboratories, Syracuse, NY), $100 \mathrm{mg} / \mathrm{kg}$ i.m.; glucose, $1 \mathrm{~g} / \mathrm{kg}$, was injected incardiacally and blood was aspirated from the heart with a 21-gauge needle. Blood for glucose was drawn at $0,15,30$, and $60 \mathrm{~min}$, and blood for insulin was drawn at 0 and $1.0 \mathrm{~min}$ after injection. Blood was collected in microcentrifuge tubes, immediately centrifuged, and the plasma frozen for assay of insulin by radioimmunoassay and serum frozen for glucose by the glucose oxidase method using a glucose analyzer 2 (Beckman Instruments, Inc., Fullerton, CA) at a later date (22).

Statistical analyses. Experiments were designed to test for statistical significance by the group or paired $t$ test and analyses of variances using an Apple Ile computer and Microstat (statistics package) developed by 
Ecosoft, Inc., Indianapolis, IN. Comparisons between groups to be made were established before the experiments were conducted. Independent and multiple comparisons were made and analyses of differences between groups were calculated $(23,24)$.

Morphological studies. Pancreases of 55-d-old male rats from one rat chow control, five vitamin A-deficient rats at weight plateau for 14$20 \mathrm{~d}$, and one retinol-repleted rat, which was pair fed to the vitamin Adeficient rats, were fixed in Bouin's solution, dehydrated in graded ethanols, embedded in paraffin and cut into 5- $\mu \mathrm{m}$ thick sections. In each pancreas, at least two series of four consecutive sections (the series were cut throughout the gland at $200 \mu \mathrm{m}$ distance) were processed for indirect immunofluorescence using the following antisera and dilutions: ( $a$ ) guinea pig anti-insulin (Dr. P. H. Wright, Indiana University, Indianapolis, IN) 1:200; (b) rabbit antiglucagon (Dr. L. Heding, Novo Research Institute, Copenhagen, Denmark) 1:100; (c) rabbit anti-somatostatin (Dr. R. Guillemin, Salk Institute, San Diego, CA) 1:1600; (d) rabbit anti-pancreatic polypeptide (Dr. R. E. Chance, Lilly Research Labs, Indianapolis, IN) 1:1,000. Each section was incubated for $2 \mathrm{~h}$ at room temperature with one of these antisera, rinsed in PBS and then exposed to either antirabbit or antiguinea pig globulins labeled with fluorescein isothiocyanate and diluted 1:200, for $1 \mathrm{~h}$ at room temperature. Sections were finally rinsed in PBS, coverslipped in 4\% $n$-propyl gallate in glycerin and observed for fluorescence in an Orthoplan microscope equipped with a Ploemopak condensor (E. Leitz, Inc., Rockleigh, NJ). The specificity of the immunofluorescent staining was tested by incubating some sections with antisera preabsorbed with their respective antigens. No staining was seen under such conditions.

\section{Results}

Effects of vitamin $A$ deficiency on food intake, body weight and insulin secretion in vitro. Rats placed on a vitamin A-deficient diet for $14 \mathrm{~d}$ during the test period ate the same amount of food, but continued to show a weight plateau, with a mean weight gain of $8.9 \pm 4.1 \mathrm{~g}$ (Table I). Both phases of insulin release from islets of vitamin A-deficient rats were markedly impaired (Fig. 2).

Effects of all trans-retinoic acid and retinyl palmitate repletion on body weight, food intake, and insulin secretion in vitro. The effects of repletion of vitamin A-deficient rats during the 14-d test period with either all trans-retinoic aicd, $2-\mu \mathrm{g} / \mathrm{g}$ diet or retinyl palmitate, $4-\mu \mathrm{g} / \mathrm{g}$ diet, are shown in Table $\mathrm{I}$.

There were no significant differences in food intake or weights between rats treated with retinoic acid, $2 \mu \mathrm{g} / \mathrm{g}$ and rats treated with retinyl palmitate, $4 \mu \mathrm{g} / \mathrm{g}$ diet (Table I).

Table I. The Effects of Repletion of Vitamin A-deficient Rats with All-trans RA and RP for $14 d$ on Weight and Food Intake

\begin{tabular}{lllll}
\hline Experiment & $\mathrm{Wt}_{\mathrm{o}}$ & $\mathrm{Wt}_{\mathrm{t} 4}$ & $\Delta \mathrm{Wt}$ & $\begin{array}{l}\text { Average } \\
\text { food intake }\end{array}$ \\
\hline & $\mathrm{g}$ & $\mathrm{g}$ & $\mathrm{g}$ & $\mathrm{g} / \mathrm{d}$ \\
Vitamin A deficiency & 304 & 313 & 8.9 & 19.9 \\
$(7)$ & \pm 7.5 & \pm 6.2 & \pm 4.1 & \pm .9 \\
All trans-RA, $2 \mu \mathrm{g} / \mathrm{g}$ & 331 & $361^{\ddagger}$ & $29.6^{\ddagger}$ & 17.4 \\
$(11)$ & \pm 14.9 & \pm 10.9 & \pm 4.5 & \pm .8 \\
$\mathrm{RP}, 4 \mu \mathrm{g} / \mathrm{g}(12)$ & 316 & $351^{*}$ & $35.3^{\ddagger}$ & 18.9 \\
& \pm 13.9 & \pm 11.4 & \pm 5.5 & \pm .6
\end{tabular}

Vitamin A deficient rats grew slower than repleted rats. RA $2 \mu \mathrm{g} / \mathrm{gm} /$ diet substituted for $\mathrm{RP}$ in promoting growth. $\mathrm{Wt}_{\mathbf{0}}$, weight at beginning of period. $\mathrm{Wt}_{14}$, weight at end of test period. $\Delta \mathrm{Wt}$, weight gain during test period.

* $P<0.05$.

${ }^{\ddagger} P<0.01$ for significant differences between means of repleted rats and vitamin A deficient rats. Number of rats in parentheses.
Biphasic insulin release from islets of rats repleted with retinoic acid $2 \mu \mathrm{g} / \mathrm{g}$ diet, for $14 \mathrm{~d}$ was impaired (1st phase, 1.17士.19; 2nd phase, $6.76 \pm 1.53 \mu \mathrm{U} /$ islet) compared to release from islets of vitamin A-deficient rats repleted with retinyl palmitate (1st

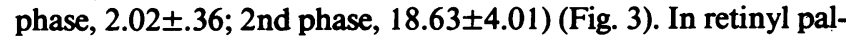
mitate-repleted rats, release from islets was biphasic but acute phase release was slightly blunted.

Effects of increasing retinoic acid to $8 \mu \mathrm{g} / \mathrm{g}$ diet on insulin secretion in vitro. Biphasic insulin release from islets of rats repleted with retinoic acid, $8 \mu \mathrm{g} / \mathrm{g}$, for the $14-\mathrm{d}$ test period was comparable (and greater than at $10 \mathrm{~min}$ ) to secretion from islets of rats repleted with retinyl palmitate, $4 \mu \mathrm{g} / \mathrm{g}$ diet (Fig. 4).

Rats treated with $2 \mu \mathrm{g} / \mathrm{g}$ retinoic acid (retinol-deficient rats) thus weighed the same and had similar food intake as rats repleted with retinyl palmitate, $4 \mu \mathrm{g} / \mathrm{g}$ diet. However, this small doseage of retinoic acid did not substitute for retinyl palmitate in insulin secretion. A larger doseage of retinoic acid substituted for retinyl palmitate in insulin secretion.

Effects of vitamin A deficiency and repletion on the concentration of retinoid binding proteins in islets. The levels of immunoreactive CRBP and CRABP in islet homogenate are shown in Fig. 5. Values found in normal islets are shown for comparison with values found in islets of vitamin A-deficient and retinoic acid, and retinyl palmitate-treated rats. The mean concentration of CRBP, but not CRABP, in islets from vitamin A-deficient rats was much lower than that found in normal islets. In islets of rats repleted with retinoic acid, $2 \mu \mathrm{g} / \mathrm{g}$ diet or retinyl palmitate, $4 \mu \mathrm{g} / \mathrm{g}$ diet, all cellular retinoid-binding proteins increased but not significantly.

Effects of vitamin $A$ deficiency and repletion on the concen-

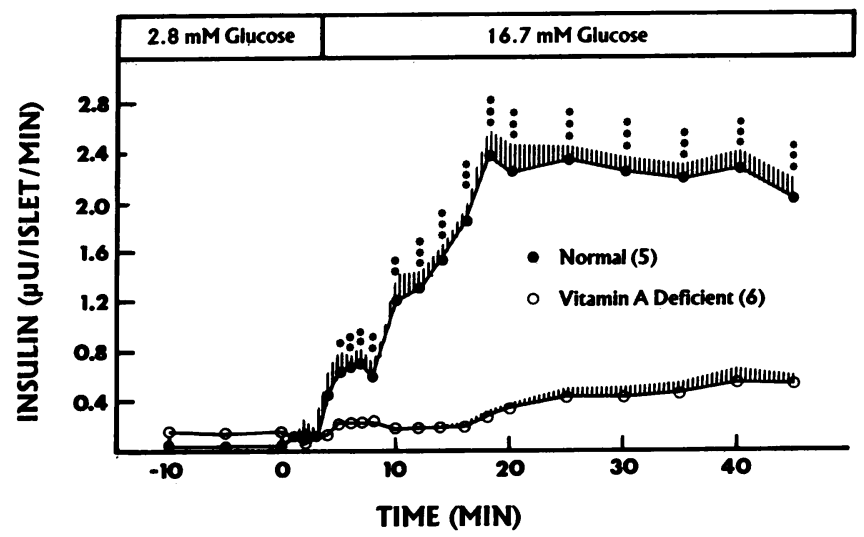

Figure 2. The effects of vitamin A-deficiency on glucose-induced biphasic insulin release. During a pretreatment or washout period, islets are perifused for $60 \mathrm{~min}$ in basal media containing $2.8 \mathrm{mM}$ glucose. At zero time the media was changed to test media. The horizontal bar at the top of the figure indicates the concentration of glucose. Insulin was assayed at the points indicated from $10 \mathrm{~min}$ before zero time to 45 min. Rats were bred from mothers made vitamin A-deficient after mating. Pups were kept on a vitamin A-free diet until day 51 at which time their weights plateaued. The rats were then put through one cycle of RA supplementation and deficiency ( $18 \mathrm{~d}$ on and $10 \mathrm{~d}$ off). The rats were then continued on a vitamin A-free diet for an additional 14 $\mathrm{d}$ after which they were killed, and their islets isolated and perifused. Islets from vitamin A-deficient rats showed decreased first and second phase insulin release in comparison to normal rat islets. The hatched area indicates $\pm 1 \mathrm{SEM}$ for the number of experiments, $\mathrm{N}=(\quad) \cdot{ }^{*} P$ $<.05 ;{ }^{* *} P<.01 ;{ }^{* * *} P<.001$. The design of the perifusion and illustration are the same in subsequent figures unless otherwise indicated. 


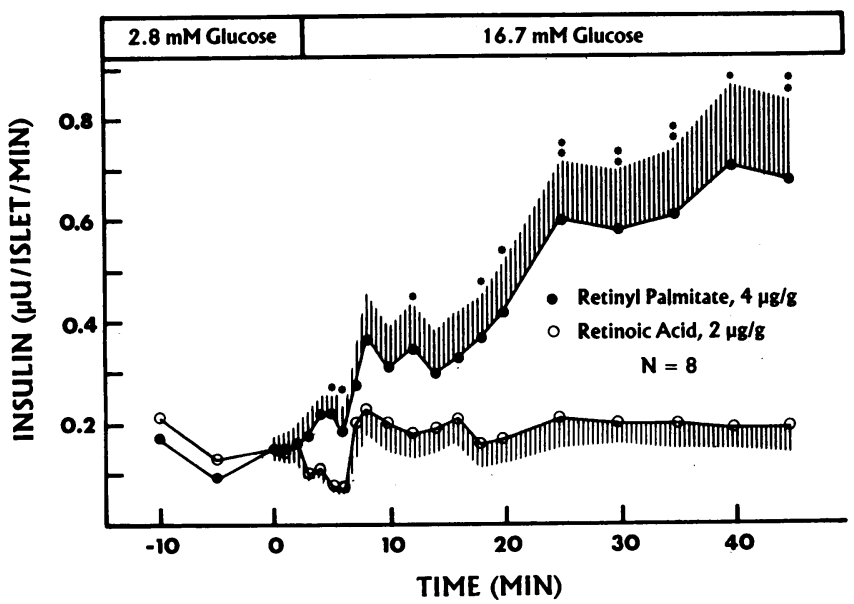

Figure 3. The effects of RP, $4 \mu / \mathrm{g}$ diet, and RA repletion, $2 \mu \mathrm{g} / \mathrm{g}$ diet, on glucose-induced biphasic insulin release. The rats were bred and treated as above with the exception that the retinoate cycle started at day 75 of vitamin A deficiency (as in Fig. 1). At the completion of one cycle ( 18 on, 10 off), the rats were then divided into two groups. One group of vitamin A-deficient rats was placed on retinoic acid, $2-\mu \mathrm{g} / \mathrm{g}$ diet, for $14 \mathrm{~d}$ and the other group of vitamin A-deficient rats placed on retinyl palmitate, $4-\mu \mathrm{g} / \mathrm{g}$ diet, for $14 \mathrm{~d}$. Body weights of the two groups at death were not significantly different. Islets from vitamin Adeficient rats treated with RA showed decreased first and second phase insulin release. Biphasic secretion from islets of rats treated with RP was markedly increased compared to secretion from islets of RAtreated rats.

tration of protein and insulin in islets (Table II). The insulin and protein contents of islets were not statistically different between normal, vitamin A-deficient or repleted vitamin A-deficient rats.

Effects of vitamin A deficiency and repletion on glucose tolerance and insulin secretion in vivo. Plasma insulins and serum glucose at zero time were not significantly different between groups (Fig. 6). After glucose injection, mean serum glucoses were more variable and higher in vitamin A-deficient and repleted groups throughout the study compared to normal rats. $15 \mathrm{~min}$ after the glucose injection, the serum glucose was higher in vitamin A-deficient rats than in control rats (Fig. 7) $(P<0.05)$. Also at $15 \mathrm{~min}$, the serum glucoses in rats repleted with retinoic acid or retinyl palmitate were lower than the serum glucose of vitamin A-deficient rats $(P<0.05)$. The peak plasma insulin one minute after glucose injection was decreased in vitamin A-

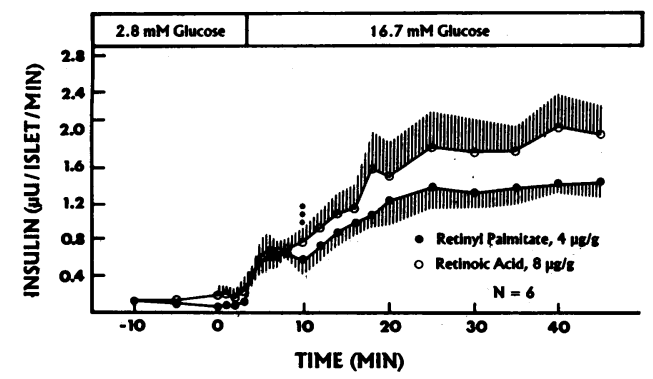

Figure 4. The effects of retinoic acid repletion, $8 \mu \mathrm{g} / \mathrm{g}$ diet on glucoseinduced insulin release. The design is the same as that shown in Fig. 3, except that the dose of RA was increased to $8 \mu \mathrm{g} / \mathrm{g}$ diet during the test period. Secretion from islets of RA-treated rats was not signifcantly different from islets of RP-treated rats except at $10 \mathrm{~min}$.

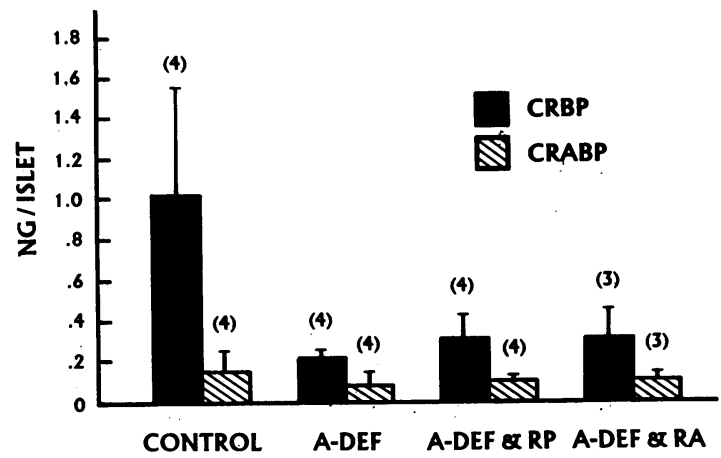

Figure 5. The effects of vitamin A deficiency on CRBP and CRABP. CRBP was markedly decreased in islets of vitamin A-deficient rats $(P$ $<0.05$ ). Treatment with RP or RA increased CRBP but not significantly. CRABP was not affected by vitamin A deficiency or treatment.

deficient rats (Fig. 7) $(P<0.01)$. Compared to vitamin A-deficient rats, retinyl palmitate repletion, but not retinoic acid repletion, significantly increased peak plasma insulin $(P<0.02)$.

Effects of vitamin $A$ deficiency on pancreatic morphology. The islets appeared normal in size, number and structure by conventional light microscopy (Fig. 8, $A$ ). Observations of at least 30 islets per pancreas $(n=5)$ after immunostaining for the four main islet hormones failed to reveal obvious changes in the topographical and numerical relationships of the main islet cell types. As in controls, the insulin-containing B cells were thus the preponderant cell type in the islets of the vitamin A-deficient rats and formed the major part of their cores (Fig. 8, B). The glucagon-containing A cells (Fig. 8, C), the somatostatin-containing D cells and the pancreatic polypeptide-containing cells were less numerous and were intermixed at the periphery of the islets. (In preliminary studies, on conventional microscopy, pancreases from vitamin A-deficient cycled rats had changes in the exocrine pancreas. Detailed morphological and functional studies of the exocrine pancreas are planned and will be reported separately.)

No obvious structural alteration was detected in the pancreas of one vitamin A-deficient rat that was pair fed a retinol-repleted diet.

\section{Discussion}

Our results indicate that insulin release in vitro from islets of vitamin A-deficient rats is markedly impaired in response to

Table II. The Effects of Vitamin A Deficiency and Repletion with RA and RP on Protein and Insulin Content of Isolated Islets

\begin{tabular}{lll}
\hline Experimental group & Protein & Insulin \\
\hline & $n g /$ islet & $\mu U /$ islet \\
Normal & $380 \pm 120(4)$ & $808 \pm 88(8)$ \\
A-deficiency & $180 \pm 20(4)$ & $820 \pm 67(7)$ \\
Retinoic acid $2 \mu \mathrm{g} / \mathrm{g}$ & $210 \pm 80(3)$ & $796-218(5)$ \\
Retinyl palmitate $4 \mu \mathrm{g} / \mathrm{g}$ & $160 \pm 50(4)$ & $905 \pm 286(4)$
\end{tabular}

The islet concentrations of protein and insulin were not significantly different between groups. Values in parentheses are the number of batches of islets studied. 


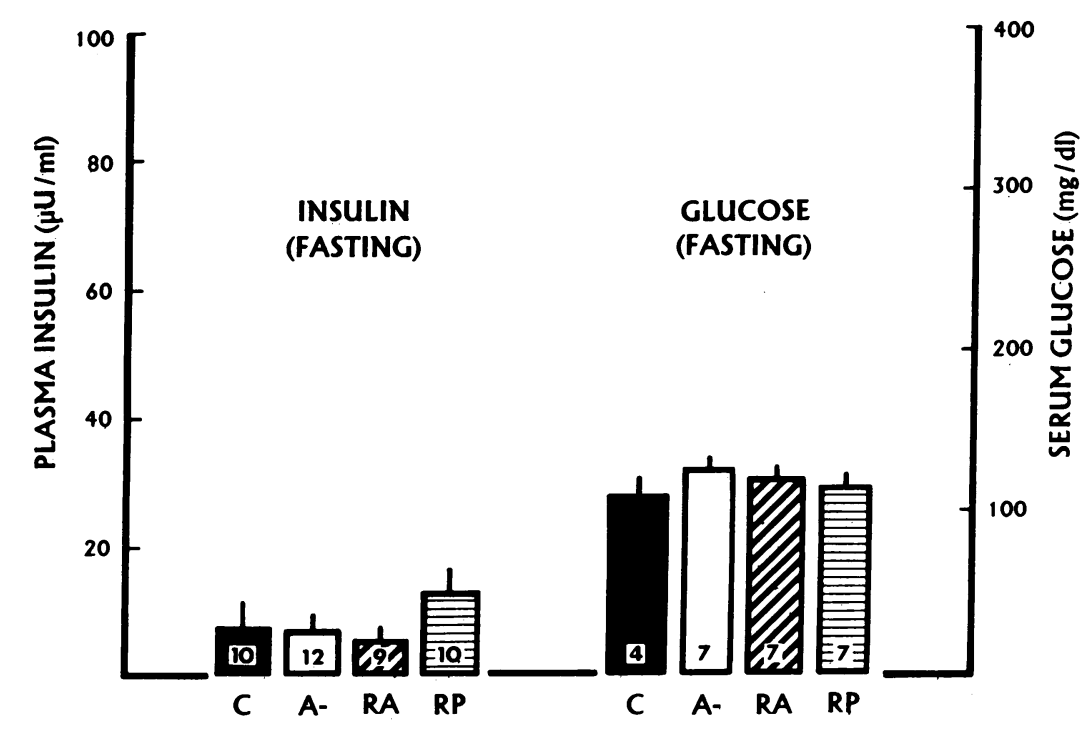

Figure 6. The effects of vitamin A deficiency and repletion on fasting plasma insulin and serum glucose. Prior to injection of glucose, blood was drawn for fasting serum glucose and plasma insulin. Differences between group means were not significant. $C$, normal rats; $A$-, vitamin A-deficient rats; $R A$, retinoic acid-repleted rats; $R P$, retinyl palmitate-repleted rats for Figs. 6 and 7. glucose. Retinoic acid at $2-\mu \mathrm{g} / \mathrm{g}$ diet did not reverse the impairment in vitro. However, with a larger dose of retinoic acid, 8$\mu \mathrm{g} / \mathrm{g}$ diet, insulin secretion was comparable to that from islets of retinyl palmitate-treated rats. Hence, retinol is required for insulin release, but retinoic acid at adequate replacement doses, can substitute for retinol in insulin secretion.

Because insulin secretion is dependent upon adequate food intake and is impaired in states of food restriction and semistarvation (11), we needed a vitamin A-deficient model in which nonspecific effects of vitamin A deficiency on weight loss and, in turn, insulin release are minimized. Our model was satisfactory in that although vitamin A-deficient rats gained less weight, they ate the same amount of food as control rats, and yet had

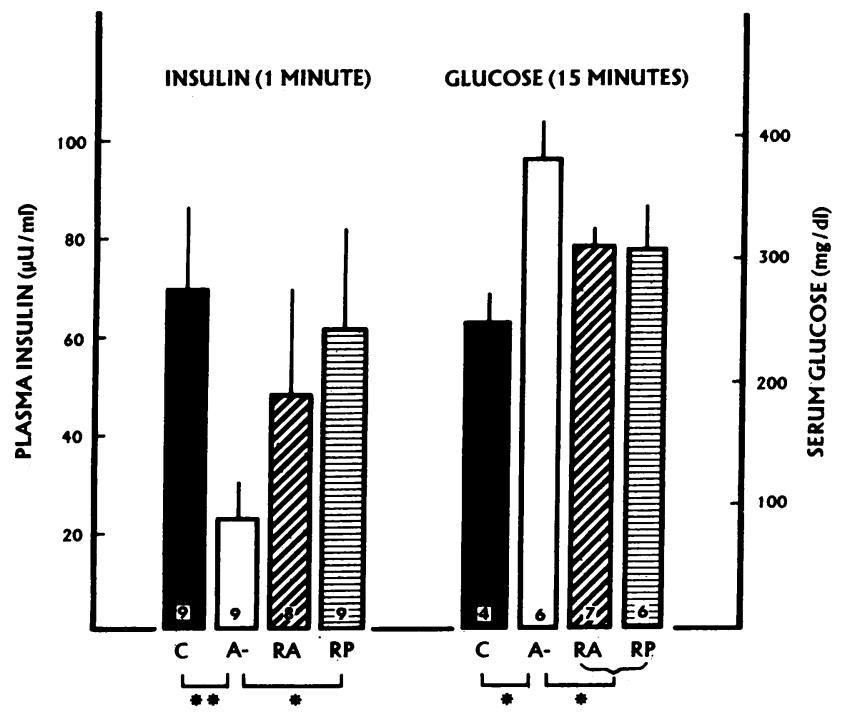

Figure 7. The effects of vitamin A deficiency and repletion on glucoseinduced insulin release and glucose tolerance. Glucose, $1.0 \mathrm{~g} / \mathrm{kg}$, was injected intracardiacally. Plasma insulin was measured $1.0 \mathrm{~min}$ after and serum glucose 15 min after injection of glucose. Vitamin A-deficient rats showed decreased insulin release compared with normal $(P$ $<0.01)$ and RP-repleted $(P<0.02)$ rats. Vitamin A-deficient rats had an increase in serum glucose compared with normal and both RAand RP-repleted rats $(P<0.05)$. impaired insulin release. More importantly, rats repleted with retinoic acid, $2-\mu \mathrm{g} / \mathrm{g}$ diet, ate the same amount of food and gained the same amount of weight as rats repleted with retinyl palmitate, $4-\mu \mathrm{g} / \mathrm{g}$ diet. Therefore under conditions of similar food intake, weight gain and body weight, retinoic acid, $2 \mu \mathrm{g} / \mathrm{g}$ diet did not substitute for retinyl palmitate, indicating that the impairment of insulin release in vitro was a result of retinol deficiency and not due to decreased food intake and impaired growth.

One possible explanation for the impairment of insulin secretion is that vitamin A deficiency results in a change in the quality of pancreatic tissue which could conceivably increase collagenase digestion of the pancreas and islets, and in turn, impair islet function. This does not appear to be the case. The pancreases of vitamin A-deficient rats and rats treated with retinoic acid, $2 \mu \mathrm{g} / \mathrm{g}$, were not different from control pancreases of rats repleted with retinyl palmitate, $4 \mu \mathrm{g} / \mathrm{g}$, or retinoic acid, 8 $\mu \mathrm{g} / \mathrm{g}$. Yet, islets from vitamin A-deficient and $2-\mu \mathrm{g} / \mathrm{g}$ retinoic acid-treated rats secreted less insulin. Further, our in vivo data support our in vitro findings. In vivo, vitamin A-deficient rats demonstrated impairment of acute insulin release and impaired glucose tolerance at $15 \mathrm{~min}$, indicating that a defect in insulin release is evident prior to islet preparation. This defect in insulin release was reversed by retinyl palmitate repletion but not retinoic acid repletion. The in vivo findings support the conclusion that the in vitro defect is related to a specific action of vitamin A and its deficiency in vivo.

Whereas a defect in insulin release was observed in vitamin A-deficient rats both in vivo and in vitro, and this defect was improved with retinyl palmitate repletion but not with retinoic acid repletion, both retinyl palmitate- and retinoic acid-repleted rats showed improved glucose tolerance compared with A-deficient rats. The improvement in glucose tolerance in retinoic acid-repleted rats may be related to decreases in activity of the sympathetic nervous system (25) or other glucose counterregulatory hormones upon repletion. The lack of a difference in glucose tolerance between retinyl palmitate-repleted and retinoic acid-repleted rats may be due to the lack of specificity of glucose tolerance testing for insulin secretion.

The mechanism by which vitamin A deficiency impairs insulin release remains to be determined. The absence of changes in the overall appearance and hormone content of the islets on 

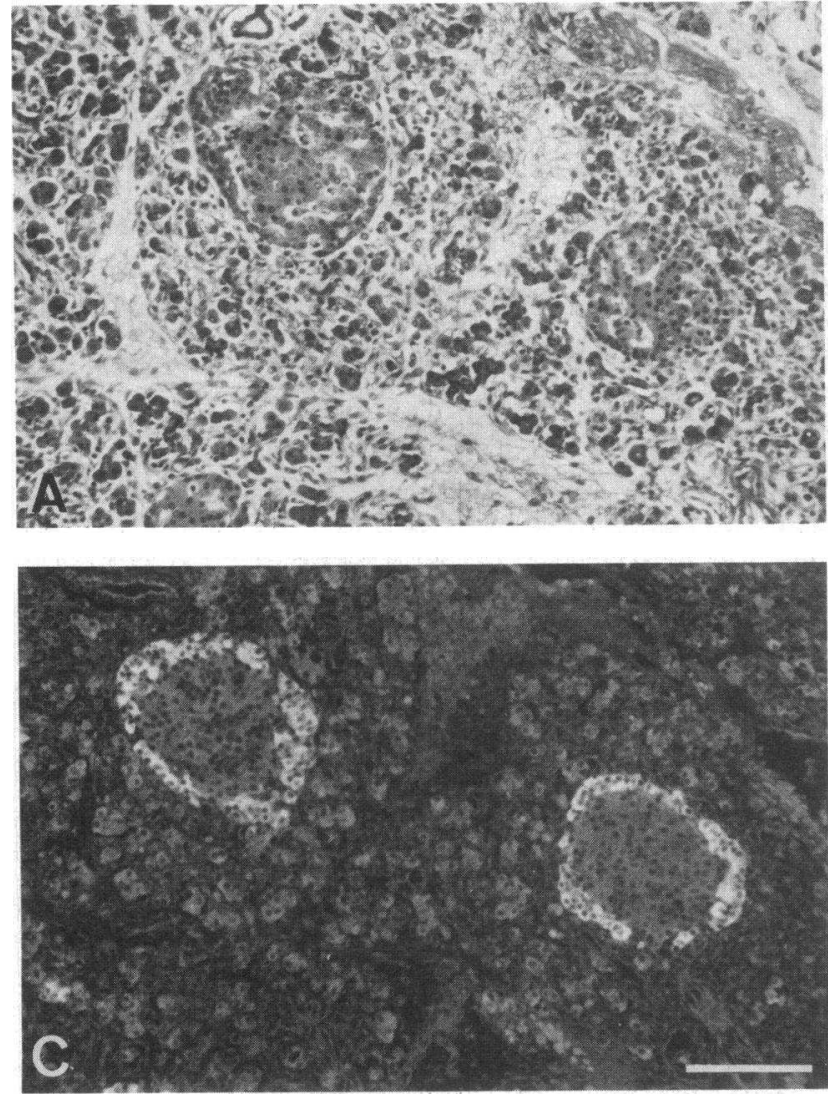

staining with antisera, as well as the normal insulin and protein content suggest the effects of vitamin A deficiency are not nonspecific effects of damage or decreased hormone synthesis and may be due to a specific functional defect. Vitamin $A$ is involved in gene expression and the synthesis of proteins and glycoproteins (2). Deficiency of vitamin A could lead to impaired synthesis of proteins, either directly or indirectly related to microfilamentous function (26), or membrane glycoproteins (2). In epithelial cells, vitamin $A$ is known to induce the synthesis of different keratins (27-29). Although nothing is known about vitamin A-induced syntheses of mRNA and its gene products in islets, the identification of a $60-\mathrm{kD}$ intermediate filamentous protein as an islet keratin (30) provides an exciting starting point to examine the possible regulatory effects of vitamin A on islet mRNA and protein synthesis. This islet protein is associated with the cytoskeleton of the hamster insulinoma cell (31) and undergoes calciumand cyclic-AMP regulated phosphorylation by an islet protein kinase concomitant with insulin release (32). If vitamin A regulates the synthesis of this keratin and this keratin is part of the islet cytoskeleton, a deficiency of vitamin A could lead to decreased keratin and, in turn, a defect in microfilament function and insulin release. Another possibility is that vitamin A regulates and induction of islet transglutaminase, an enzyme that catalyzes the crosslinking of proteins, possibly microfilamentous proteins. Vitamin A is known to alter the expression of tissue transglutaminase in epithelial cells (33) and leukemic cells (34). Islet transglutaminase has been proposed to have a role in regulating the access of beta cell granules to exocytic sites (35). If retinoids affect islet transglutaminase, then vitamin A may be involved in regulating the release of insulin granules.

Previous studies have demonstrated the presence of retinoid

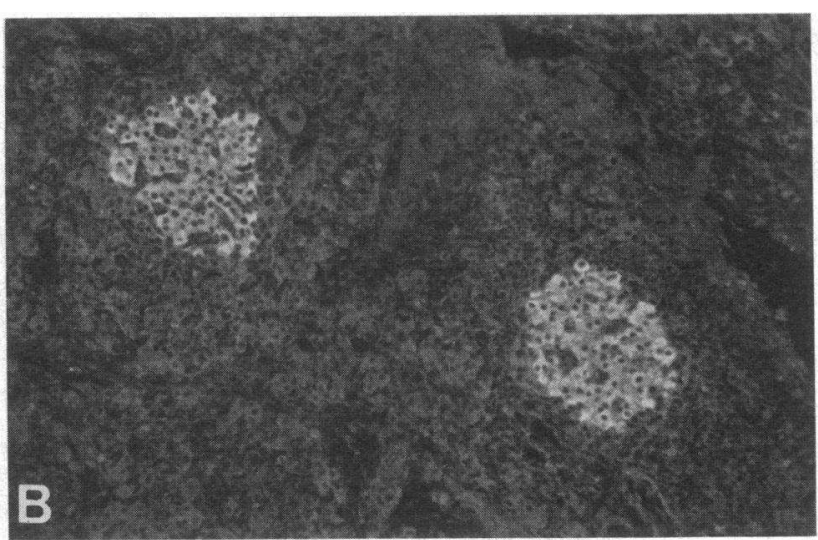

Figure 8. Consecutive sections of the pancreas of a vitamin A-deficient rat stained with Hematoxylin-Eosin $(A)$ and with a specific serum against insulin $(B)$ and glucagon $(C)$. The two islets of Langerhans seen in this field are normal in appearance. The immunostain show that the insulin-containing B cells were the most abundant islet cells and were located predominantly in the central core of the islets $(B)$. The glucagon-containing A-cells were less numerous and were located mostly at the periphery of the islets $(C)$. The bar represents $100 \mu \mathrm{m}$.

binding proteins in normal islets (7). The present studies confirm those findings and demonstrate the presence of these binding proteins in vitamin A-deficient islets. The concentration of CRBP was decreased in islets of vitamin A-deficient rats. This raises the possibility that CRBP might be influenced by dietary vitamin $A$. With acute repletion of over $2 \mathrm{wk}$, the concentrations of binding proteins did not increase significantly; longer periods of vitamin A repletion may be required to increase islet levels. The findings that islet CRBP is present in much higher concentration than CRABP, and CRBP but not CRABP is reduced in vitamin A deficiency are supported by and consistent with similar findings in other tissues (20). The two proteins differ widely in their tissue distribution and concentration and may serve different functions in different cells. Also CRBP in many different tissues is reduced quite significantly by total retinoid deficiency (20), whereas CRABP is not influenced by dietary retinoid availability.

The presence of high levels of both CRBP and CRABP in islets and impairment of insulin release as a result of vitamin A deficiency suggest that the islets may be a target site of action for vitamin A and that vitamin A may have a role in islet function and insulin release. More information is needed regarding the distribution of retinoid binding proteins in different types of islet cells and the secretion of glucagon and somatostatin. Whether retinoids also play a role in islet cell growth and differentiation in fetal and adult islets as in other cells, deserves further investigation because of the relevance to abnormal islet growth, diabetes mellitus, and islet transplantation. Preliminary data (36) indicating that CRBP is selectively concentrated in the anterior pituitary gland suggest that retinoids may be important in hormone secretion from other endocrine glands. 


\section{Acknowledgments}

We thank Dr. Jane Grey and Mr. D. J. Morakis for excellent technical assistance and Carolyn Endicott for typing the manuscript.

P.M. was supported by fellowship 83.896.0.81 and grant 3.460.83 from the Swiss National Science Foundation and by the National Institutes of Health grant 5R01-AM-30519-02.

\section{References}

1. Goodman, D. 1984. Vitamin A and retinoids in health and disease. N. Engl. J. Med. 310:1023-1031.

2. Wolf, G. 1984. Multiple functions of vitamin A. Physiol. Rev. 64: 873-1053.

3. Lotan, R. 1980. Effects of vitamin A and its analogs (retinoids) on normal and neoplastic cells. Biochim. Biophys. Acta. 605:33-91.

4. Wald, G. 1968. The molecular basis of visual excitation. Nature (Lond.). 219:800-807.

5. Chytil, F., and D. E. Ong. 1984. Cellular retinoid-binding proteins. In The Retinoids. M. G. Sporn, A. B. Roberts, and D. S. Goodman. Academic Press, Inc., Orlando, FL. 90-123.

6. Goodman, D. S. 1984. Plasma-retinol binding protein. In The Retinoids. M. B. Spurn, A. B. Roberts, and D. S. Goodman, editors. Academic Press, Orlando, FL. 2:41-88.

7. Kato, M., K. Kato, W. S. Blaner, B. S. Chertow, and D. S. Goodman. 1985. Plasma and cellular retinoid-binding proteins and transthyretin (prealbumin) are all localized in the islets of Langerhans in the rat. Proc. Natl. Acad. Sci. USA. 82:2488-2492.

8. Chertow, B. S., and G. R. Baker. 1978. The effects of vitamin A on insulin release and glucose oxidation in isolated rat islets. Endocrinology. 103:1562-1572.

9. Chertow, B. S., R. J. Bushchmann, and R. L. Kaplan. 1979. Cellular mechanisms of insulin release. Effects of retinol on insulin release and islet ultrastructure. Diabetes. 28:754-761.

10. Chertow, B. S., N. G. Baranetsky, W. I. Sivitz, P. Meda, M. D. Webb, and J. C. Shih. 1983. Cellular mechanisms of insulin release. Effects of retinoids on rat islet cell-to-cell adhesion, reaggregation, and insulin release. Diabetes. 32:568-574.

11. Zawalich, W. S., E. S. Dye, A. S. Pagliara, R. Rognstad, and F. M. Matschinsky. 1979. Starvation diabetes in the rat: onset, recovery, and specificity of reduced responsiveness of pancreasatic b-cells. Endocrinology. 104:1344-1351.

12. Olson, J. A., W. Rojanapo, and A. J. Lamb. 1981. The effect of vitamin A status on differentiation and function of goblet cells in the rat intestine. Ann. NY Acad. Sci. 359:181-191.

13. Lamb, A. J., A. Piyaratana, and J. A. Olson. 1974. Induction of rapid, synchronous vitamin A-deficiency in the rat. J. Nutr. 104:11401148.

14. Anzano, M. A., A. J. Lamb, and J. A. Olson. 1979. Growth, appetite, sequence of pathological signs and survival following the induction of rapid, synchronous vitamin A-deficiency in the rat. J. Nutr. 109:1419-1431.

15. Suda, T., H. F. De Luca, and Y. Tanaka. 1970. Biological activity of 25-hydroxycholecalciferol in rats. J. Nutr. 100:1049-1052.

16. Chertow, B. S., W. I. Sivitz, N. G. Baranetsky, S. A. Clark, A. Waite, and H. F. De Luca. 1983. Cellular mechanisms of insulin release: the effects of vitamin D-deficiency and repletion on insulin secretion. Endocrinology. 113:1511-1518.

17. Yalow, R. S., and S. A. Berson. 1960. Immunoassay of endogenous plasma insulin in man. J. Clin. Invest. 39:1157-1175.
18. Herbert, V., K. Lau, C. W. Gottlieb, and S. J. Bleicher. 1965. Coated charcoal immunoassay of insulin. J. Clin. Endocrinol. Metab. 25:1375-1384.

19. DeRuyter, M. G. M., and A. P. De Leenheer. 1978. Simultaneous determination of retinol and retinyl esters in serum or plasma by reversedphase high-performance liquid chromatography. Clin. Chem. 24:19201923.

20. Kato, M., W. S. Blaner, J. R. Mertz, K. Das, K. Kato, and D. S. Goodman. 1985. Influence of retinoid nutritional status on cellular retinol- and cellular retinoic acid-binding protein concentrations in various rat tissues. J. Biol. Chem. 260:4832-4838.

21. Bradford, M. M. 1976. A rapid and sensitive method for the quantitation of microgram quantities of protein utilizing the principle of protein-dye binding. Anal. Biochem. 72:248-254.

22. Washko, M. E., and E. W. Rice. 1961. Determination of glucose by an improved enzymatic procedure. Clin. Chem. 7:542-545.

23. Dowdy, S., and S. Wearden. 1983. Statistics for Research. John Wiley and Sons, Inc., New York. pp. 537.

24. Godfrey, K. 1985. Statistics in practice. Comparing the means of several groups. N. Engl. J. Med. 313:1450-1456.

25. Nakano, K., and R. Mizutani. 1984. Increased sympathetic nervous system activity in rat spleen and heart following vitamin A depletion. J. Nutr. Sci. Vitaminol. 80:163-170.

26. Mordan, L. J., S.-K. Hui, and J. S. Bertram. 1984. Modulation by retinyl acetate of microfilament bundle formation in $\mathrm{C} 3 \mathrm{H} / 10 \mathrm{~T} 1 / 2$ cells. J. Cell. Biochem. 24:15-25.

27. Fuchs, E., and H. Green. 1981. Regulation of terminal differentiation of cultured human keratinocytes by vitamin A. Cell. 25:617625.

28. Kim, K. H., F. Schwartz, and E. Fuchs. 1984. Differences in kerating synthesis between normal epithelial cells and squamous cell carcinomas are mediated by vitamin A. Proc. Natl. Acad. Sci. USA. 81: 4280-4284.

29. Eckert, R. L., and H. G. Green. 1984. Cloning of cDNA specifying vitamin A-responsive human keratins. Proc. Natl. Acad. Sci. USA. 81: $4321-4325$.

30. Schubart, U. K., and K. L. Fields. 1984. Identification of a calcium-regulated insulinoma cell phosphoprotein as an islet cell keratin. J. Cell. Biol. 98:1001-1009.

31. Schubart, U. K. 1982. Regulation of protein phosphorylation in hamster insulinoma cells. Identification of $\mathrm{Ca}^{2+}$ regulated cytoskeletal and cAMP-regulated cytosolic phosphoproteins by two-dimensional electrophoresis. J. Biol. Chem. 257:12231-12238.

32. Schubart, U. K., N. Fleischer, and J. Erlichman. 1980. $\mathrm{Ca}^{2+}$. dependent protein phosphorylation and insulin release in intact hamster insulinoma cells. Inhibition by trifluoroperazine. J. Biol. Chem. 255: 11063-11066.

33. Thacher, S. M., E. L. Coe, and R. H. Rice. 1985. Retinoid suppression of transglutaminase activity and envelope competence in cultured human epidermal carcinoma cells. Differentiation. 29:82-87.

34. Davies, P. J. A., M. P. Murtaugh, W. T. Moore, Jr., G. S. Johnson, and D. Lucas. 1985. Retinoic acid-induced expression of tissue transglutaminase in human promyelocytic leukemia (HL-60) cells. J. Biol. Chem. 260:5166-5174.

35. Sener, A., M. E. Dunlop, R. Gomis, P. C. F. Mathias, F. MalaisseLagae, and W. J. Malaisse. 1985. Role of transglutaminase in insulin release. Study with glycine and sarcosine methylesters. Endocrinology. 117:237-242.

36. Baranetsky, N. G., B. S. Chertow, W. I. Sivitz, W. S. Evans, and W. Blaner. 1985. A possible role for vitamin $A$ in pituitary function. Clin. Res. 33:269a. (Abstr.) 